\title{
Geometric facial comparisons in speed-check photographs
}

\author{
Ursula Buck • Silvio Naether • Kerstin Kreutz • \\ Michael Thali
}

Received: 25 May 2010 / Accepted: 29 September 2010 /Published online: 13 October 2010

(C) Springer-Verlag 2010

\begin{abstract}
In many cases, it is not possible to call the motorists to account for their considerable excess in speeding, because they deny being the driver on the speed-check photograph. An anthropological comparison of facial features using a photo-to-photo comparison can be very difficult depending on the quality of the photographs. One difficulty of that analysis method is that the comparison photographs of the presumed driver are taken with a different camera or camera lens and from a different angle than for the speed-check photo. To take a comparison photograph with exactly the same camera setup is almost impossible. Therefore, only an imprecise comparison of the individual facial features is possible. The geometry and position of each facial feature, for example the distances between the eyes or the positions of the ears, etc., cannot be taken into consideration. We applied a new method using 3D laser scanning, optical surface digitalization, and photogrammetric calculation of the speed-check photo,
\end{abstract}

Electronic supplementary material The online version of this article (doi:10.1007/s00414-010-0518-5) contains supplementary material, which is available to authorized users.

U. Buck $(\bowtie) \cdot$ S. Naether $\cdot$ M. Thali

University of Bern, Institute of Forensic Medicine,

Buehlstrasse 20,

CH-3012 Bern, Switzerland

e-mail: ursula.buck@irm.unibe.ch

U. Buck $\cdot$ S. Naether

Canton Police Bern, Accident service,

Schermenweg 9,

3001 Bern, Switzerland

\section{K. Kreutz}

Institut of Anthropology,

Kronzenborner Weg 14,

35429 Wettenberg, Germany which enables a geometric comparison. Thus, the influence of the focal length and the distortion of the objective lens are eliminated and the precise position and the viewing direction of the speed-check camera are calculated. Even in cases of low-quality images or when the face of the driver is partly hidden, good results are delivered using this method. This new method, Geometric Comparison, is evaluated and validated in a prepared study which is described in this article.

Keywords Forensic science - Face identification . Geometric comparison · Biometry $\cdot 3 \mathrm{D}$ scanning $\cdot$ Virtopsy

\section{Introduction}

Speeding on Swiss roads and the consequence of fatal accidents is a current and serious problem. It is ascertainable that regarding speeding accidents, the severity of the penalties delivered by the courts has increased in recent years.

Additional ways to reduce the problem of speeding are to take preventive measures and to increase the speed checks on dangerous and popular speeding road sections.

Quite often, it is not possible to call the motorist to account for their considerable excess speeding, because they deny being the driver on the speed-check photograph. In the Swiss justice system a suspect can only receive a punishment if he is identified to be the driver. The vehicle owner cannot be called to account.

In cases of speed well in excess of the speed limit, a method was searched for that helps to objectively verify whether the suspect is the photographed driver or not. The method had to be one that would be accepted and be convincing in court. 
Most commonly, the method is used in cases of administrative offenses, but identification can also be very important, if the driver on a speed-check photograph is an escaping criminal, for example after a bank raid.

In the classical anthropological photo-to-photo comparison, photographs from exactly the same view and with the same camera would be the best basis for an analysis. However, producing such photographs of the suspect is time-consuming, difficult, and, to be honest, nearly impossible [1-6]. Using these photographs, individual facial features, like the shape of the nose, the ears, the lips, etc., can be compared with those of the driver on the speedcheck photograph. Depending on the quality of the speedcheck photograph, these features are more or less clearly recorded. A true-to-scale comparison, e.g., of the nose, mouth, and cheeks and the distances between cannot be included in the whole face comparison.

Another method of facial image identification using photogrammetry, described by Lynnerup, is only possible, in case of more surveillance images from different views [7].

This study validates and evaluates a new method of driver identification using Geometric Comparison, based on 3D digitalization of the suspect's face and the car and photogrammetric analysis.

\section{Materials and methods}

One female and seven male adults (including two brothers) were photographed from an installed road-side speed-check camera. They drove five different types of cars. We used a Skoda Fabia, Toyota Avensis, VW Bus T4, Audi A4 Avant, and a Porsche Boxster.

Radar surveillance was placed in a built-up area. The cars were photographed with a speed of approximately $50 \mathrm{~km} / \mathrm{h}$. A speed-check camera (model) with a resolution of $1600 \times 1248$ pixels and a chip size of 1.5 in. was employed. The focal length was about $152 \mathrm{~mm}$, converted into $35-\mathrm{mm}$ camera format.

At least five photographs per person were taken. In at least one photograph, the driver was wearing sunglasses and in two, the driver was wearing sunglasses and a cap. In total 53 photographs were taken and analyzed.

For the 3D Geometric Comparison, each driver, as well as the brother of one of them, was digitized using a 3D optical surface scanner. The surrounding locality and the cars involved were documented using a 3D laser scanner.

3D optical surface scanning

For the three-dimensional digitalization of the faces of the presumed drivers, the optical surface-scanning system
GOM ATOS III (GOM, www.gom.com, Braunschweig, Germany) was employed (Online Resource 1.1) [8-11].

The non-contact ATOS 3D digitizing system relies on the principle of triangulation. Projected fringe patterns are observed with two cameras mounted on both sides of the projector. 3D coordinates of up to 4 million surface points per measurement are calculated with high precision. Several single measurements taken from different views and elevations are merged automatically by reference targets, stuck around or on the object, into a single data set. The ATOS software generates a polygon mesh of the object's surface.

The accuracy of the surface data depends on the applied measuring volume. In this study, we used a measuring volume of $500 \times 500 \times 500 \mathrm{~mm}$, with a resulting point spacing of $0.2 \mathrm{~mm}$. The operator always has the possibility to control the quality of the data during the processing. The scanning of each face takes about 5 to $10 \mathrm{~min}$.

In the ATOS analyzing software, polygon meshes of the faces are calculated automatically (Online Resource 1.1). The polygon meshes are thinned based on the curvatures and saved as an STL-file for import into the 3D studio max software (Version 8.0, Autodesk, www.autodesk.com/3dsmax, USA).

\section{D laser scanning}

For the 3D documentation of the locality and the cars, a 3D laser scanner Leica Scan Station 2 was utilized (Leica Geosystems, www.leica-geosystems.ch, Switzerland). Such a system allows for the generation of millions of $3 \mathrm{D}$ points in no time. The $3 \mathrm{D}$ laser scanner sends laser beams to the investigation environment whilst rotating with a horizontal angle of up to $360^{\circ}$ and a vertical angle of up to $310^{\circ}$. The scanned objects reflect the laser beams and the scanner measures their distances and angles and calculates the 3D coordinates of a huge number of surface points. A quick digitization of the investigation environment, with detailed structures, is therefore possible (Online Resource 1.2). Up to 500,000 measuring points per second can be captured in 3D. The maximum range of the employed time-of-flight laser scanner amounts to up to $300 \mathrm{~m}$.

The scanner was placed in approximately the same position as that in which the speed-check camera had been installed. The cars were scanned from the right-front side (Online Resource 1.3). The scan of the locality took about $20 \mathrm{~min}$ and of the car $5 \mathrm{~min}$. The result of the laser scanning is a $3 \mathrm{D}$ geo-orientated point cloud of the locality and of the cars, with a resolution down to less than $2 \mathrm{~mm}$. A $3 \mathrm{D}$ model of the locality was created out of the point cloud, using the Cyclone software (Leica Geosystems, www.leica-geosystems.ch, Switzerland).

3D models of the cars were generated in the ATOS software by polygonization of the point cloud. 
Photogrammetric calculation of the speed-check camera using 3D studio max

By using the camera map function in the 3D studio max software, the internal and external orientation of the speedcheck camera can be calculated. The internal orientation of the camera includes the focal length and amount of distortion of the optics. The external orientation refers to the spatial position, the angle of rotation, tilt, and roll of the camera.

This simultaneous calibration is performed by measuring identical points on the 3D model of the locality and in the speed-check photograph. At least eight points have to be measured. To increase the accuracy, 15 to 20 points were measured, which were equally distributed all over the entire photograph.

A virtual camera with the calculated parameters of the speed-check camera was placed in the created 3D scene of the locality. Now, virtual photographs could be taken from the same view and with the same resolution as the original speed-check camera photograph. To verify the accuracy of the camera calculation, the real photograph was overlaid with the virtual photograph (Online Resource $1.4 \mathrm{a}, \mathrm{b})$.

Superimposition of the cars and the faces in 3D studio max

The 3D model of the car that was photographed by the speed-check camera is placed in the $3 \mathrm{D}$ scene in the corresponding position of the car in the original photograph. After adjusting the exact position, a virtual photograph is taken using the virtual camera. The speed-check photograph can be overlaid with the virtual photograph of the 3D model of the car using the Adobe Photoshop software (Version 7.0, Adobe, www.adobe.com, USA; Online Resource 1.4c). The overlying virtual photograph can be adjusted with different values of opacity to compare the shape of the displayed 3D model of the car with the shape of the car on the speed-check photograph (Online Resource 1.5).

In the next step, the $3 \mathrm{D}$ model of the first face is placed in the 3D scene in the corresponding position which the driver, or even the front-seat passenger, had in the original photograph. Now, as with the car, a virtual photograph is taken and the speed-check photograph is overlaid with this photograph (Online Resource 1.4d). The value of opacity is adjusted to compare the features of the person's face.

Another possibility for comparison is to move the 3D model of the face step-by-step into the speed-check photograph (Fig. 1). First, the nose and parts of the mouth are visible. Then the whole mouth and the brow, in the next step the, cheek and eyes, and at last the ears. In this way,
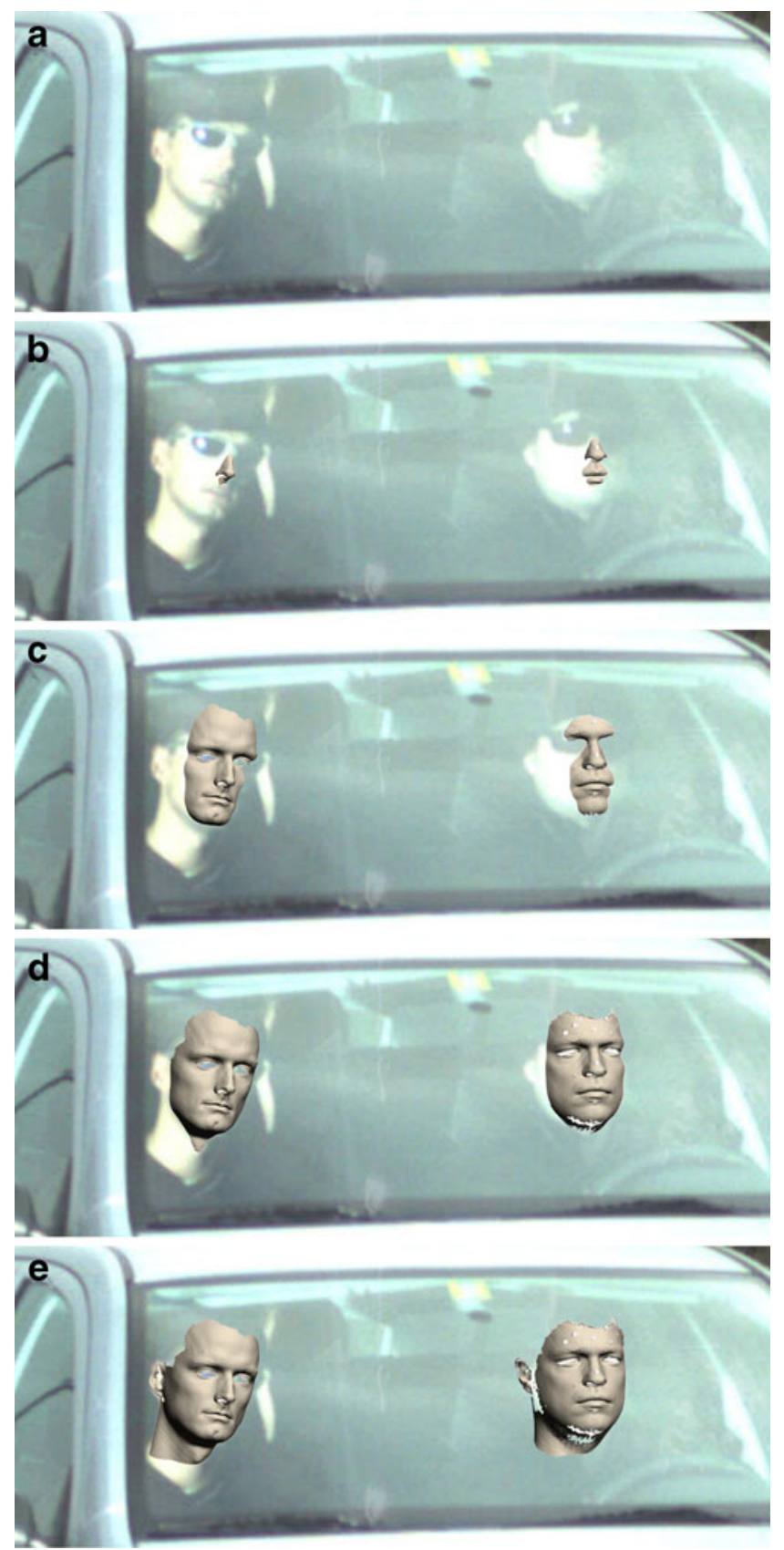

Fig. 1 Comparison of the driver and front-seat passenger of the Skoda Fabia with the corresponding suspects. Parts of the 3D model of the driver's and front-seat passenger's face are inserted step-by-step into the speed-check photograph. a The speed-check photograph. b The nose and parts of the mouth of the corresponding suspects are visible. c Comparison of the whole mouth and the brow. d Comparison of the cheeks and eyes. e Visualization of the ears

step-by-step, all the features of the person's face can be compared with those on the speed-check photograph.

This process is repeated with the $3 \mathrm{D}$ models of all the faces. The comparison is done in blind trials. The overall procedure is visualized in a schematic view (Fig. 2). 


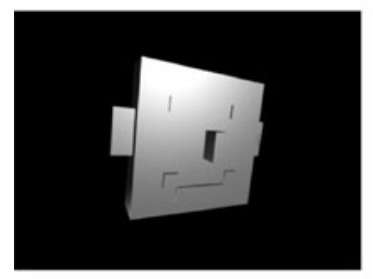

speed check photograph
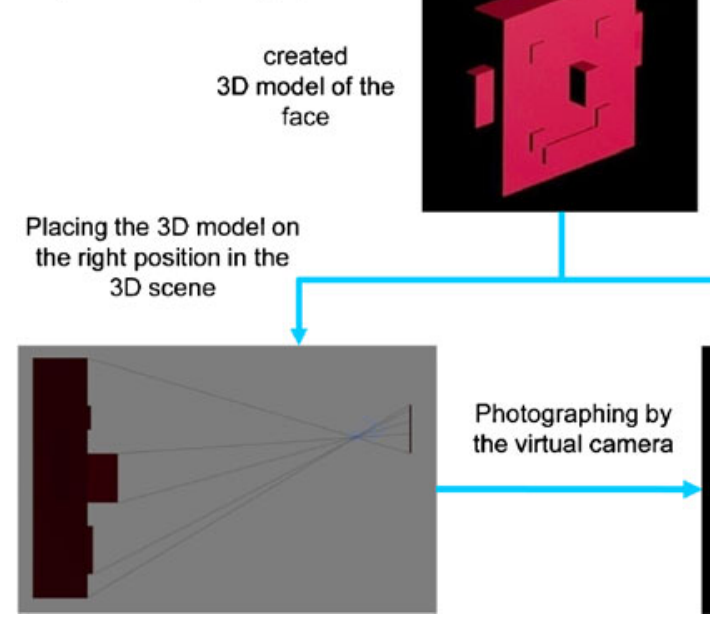

Fig. 2 Schematic visualization of the applied method

\section{Anthropological facial features comparison}

Using the described methods, the facial features of a presumed driver or front-seat passenger can be compared with those of the real driver or front-seat passenger, based on the virtual photograph of the presumed face and the speed-check photograph of the real face. The presumed driver and presumed front-seat passenger are recorded with the same camera parameters and from the same view as the driver and front-seat passenger on the speed-check photograph. In this way, not only can the individual shapes of the person's facial features be compared, but also their position and size. Important features are the shape, size, and position of the nose, eyes if visible, brow, mouth, ears, and chin. The outline shape of the face can also be an important feature for identification. Furthermore, facial wrinkles are an individual characteristic for the identification of a face. To include this characteristic, the time between the photograph and the documentation of the presumed person should not be too long.

If the features of the compared face do not correspond with the driver's face or with the front-seat passenger's face, the person can be excluded from being the driver or frontseat passenger.

If no disqualifying criterion was found, the resolution and quality of the photo and the number of recognized facial features give a "degree of correspondence". The degree is described by terms ranging from "is worthy of consideration" to "with all highest probability". The exclusion of a close blood relative is only possible if the relative is also analyzed and compared using this method.

\section{Results}

In all speed-check photographs, the faces of the driver and front-seat passenger were compared with the faces of the suspects. In each speed-check photograph the driver and respectively the front-seat passenger could be identified and all the other suspects could be excluded from being the driver or front-seat passenger (Fig. 3, Online Resource 1.6-10). Identification was also possible in these photographs where the driver and front-seat passenger wore sunglasses and/or caps.

Each speed-check photograph was analyzed by a second expert, who performed an independent comparison. In all cases, both experts achieved the same results.

Even in the cases where the driver was compared with his brother, the brother could be clearly excluded from being the driver, based on the comparison of anthropological features (Fig. 3). Some parts of the face matched the driver's face, but the shape of the chin, the outer line of the face, the mouth wrinkles, as well as the shape and position of the ear, were distinguishable from the driver's face in the speed-check photograph (Fig. 3g and h). Because of this, the brother was excluded from being the driver of the VW bus. 

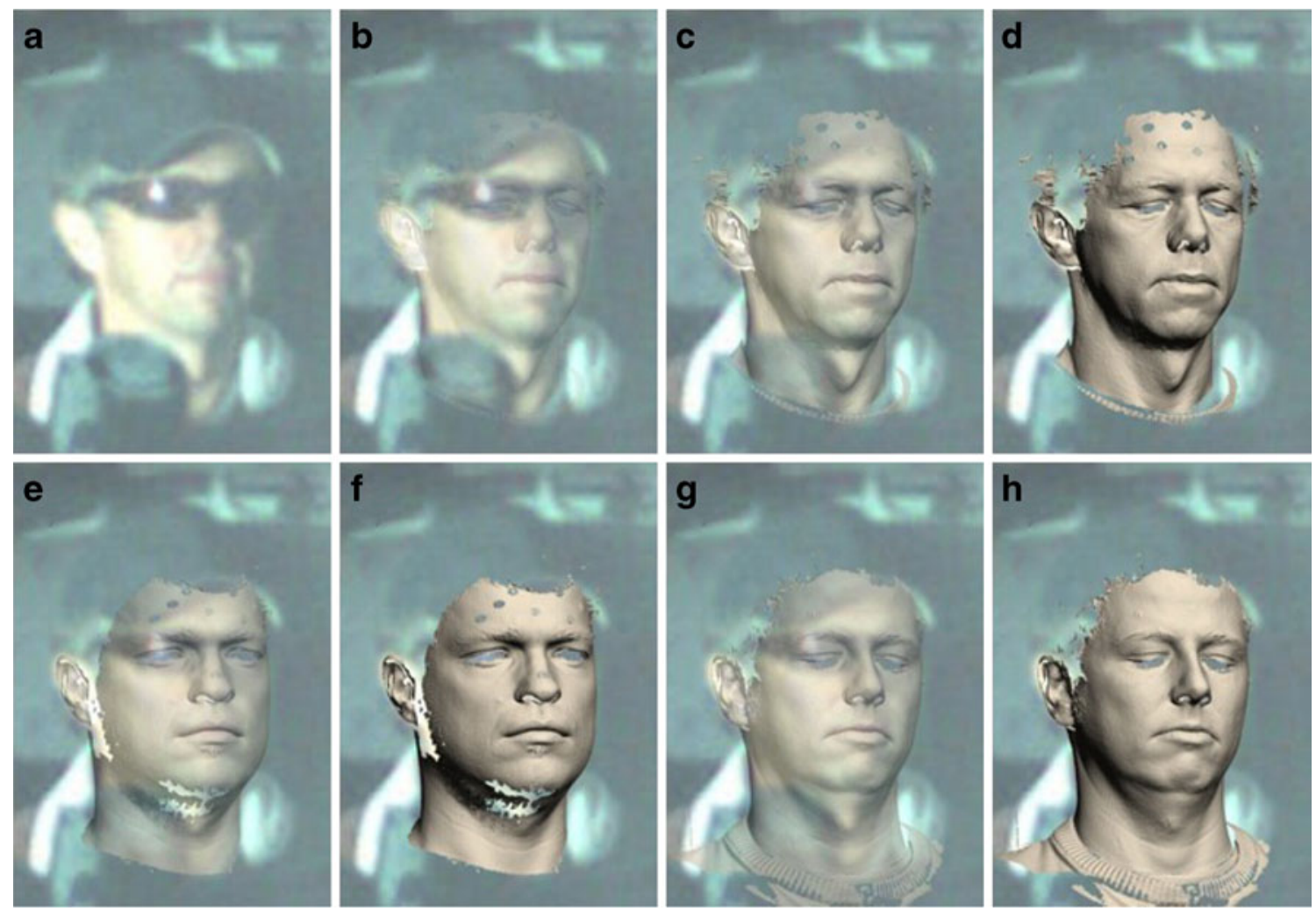

Fig. 3 Analysis of the driver of the VW bus. Comparison of the driver with possible suspects. The speed-check photograph is overlaid with the created virtual photographs of the suspects. a Close up view of the speed-check photograph. b The speed-check photograph overlaid with the 3D model of the corresponding driver with an opacity of $20 \%$. c The speed-check photograph overlaid with the 3D model of the corresponding driver with an opacity of $50 \%$. d The speed-check photograph overlaid with the 3D model of the corresponding driver. e The original photograph overlaid with the

The reconstructed 3D scene, including the correct position of the 3D model of the car in the locality and the driver's face in the car, can be viewed from different angles. These positions were reconstructed by using the speedcheck photographs. In all cases the cars were standing on the road surface and each driver's face was in the same position, particularly regarding height, as it was during the laser scanning of the car (Online Resource 1.9).

\section{Discussion}

In all cases, the correct driver could be identified. Even the brother of one driver could be clearly excluded from being the driver. The analysis of one speed-check photograph, including the photogrammetric calculation and the comparison with the presumed drivers, took about 4 to $8 \mathrm{~h}$.

Using this method of Geometric Comparison, the influence of the focal length and the distortion of the
3D model of another person with an opacity of $50 \%$. It is clearly visible that this person does not match the driver on the speed-check photograph. $\mathbf{f}$ Visualization of the excluded person with an opacity of $100 \%$. g The original photograph overlaid with the 3D model of the face of the brother of the driver with an opacity of $50 \%$. The brother can also be excluded from being the driver because of different facial features. h Visualization of the comparison with the brother of the driver with an opacity of $100 \%$

objective lens can be eliminated. The precise position and viewing direction of the speed-check camera can be reconstructed. In the classical photo-to-photo comparison, this is impossible.

Besides, a comparison of the individual shape of the nose, the ears, the eyes etc., and also an exact comparison of the geometric size and shape of the whole face and facial features, the comparison of the distances between facial features is also possible. Thus, the Geometric Comparison enables for an accurate comparison an investigation and delivers good results, even in the case of low-quality photographs or when the face of the driver is partly hidden.

Furthermore, the described method is focused on the comparison of the geometric positions and sizes of the facial features and distances between them, which are not significantly influenced by the facial expression.

In case of a long time period between the original speedcheck photograph and the $3 \mathrm{D}$ documentation of the presumed person, the possible changes of the face, 
concerning wrinkles and grooves, has to be considered in the analysis. However, a Geometric Comparison will still be possible in most cases without the features which are influenced by the time lapse.

In the classical photo-to-photo comparison several photographs of the presumed driver from different directions and distances have to be taken to get one photograph, which is similar to the speed-check photo. On the other hand, using Geometric Comparison, the 3D documentation of the face is time-saving and easy to use. The face has only to be scanned in $3 \mathrm{D}$ in order to be viewed from all directions and perspectives.

To exclude or include a close blood relative as the recorded driver, a 3D scan and a comparison of his face has to be made. Otherwise, the close blood relative cannot be excluded. This study demonstrated that Geometric Comparison is a useful tool in face identification on speed-check photographs. This method would also be a suitable tool for identification of suspects recorded by surveillance cameras.

The study was performed in cooperation with an experienced anthropologist. Anthropologic knowledge of and experience with facial feature comparison are still necessary to perform the comparison analysis using the $3 \mathrm{D}$ scanning technology. This comparison analysis is much easier and more precise than a photo-to-photo comparison.

In Switzerland, the fines for speeding can be very high, depending on the income of the driver. If the driver can be convicted, normally, the cost is paid by the driver. Therefore, the time and effort of this method is justifiable in cases of administrative offense. In addition, the fact that with this method drivers can be identified might act as a deterrent to speeding drivers.

Using this effective method of Geometric Comparison, additional valuable evidence is provided. The method has already been applied in actual cases and is accepted by the Swiss courts.
Acknowledgements The authors thank Gerhard and Urs Reichen, André Lüthi, Christian Jackowski, Danny Spendlove, Hans Mühlheim, and the speed-check team of Bern Police for their help in data collection. Many thanks also to Lowri Jones and Gary Hatch for their great support with linguistic knowledge.

\section{References}

1. Knussman R (1988) Methoden des morphologischen Vergleichs in der forensischen Anthropologie. Gustav Fischer, Stuttgart, pp 386-407

2. Thomas CDL (1998) Quantification of facial shape and form. Arnold, London, pp 165-176

3. Iscan MY (1993) Introduction of techniques for photographic comparison: potential and problems. Wiley-Liss, New York, pp $57-70$

4. Halberstein RA (2001) The application of anthropometric indices in forensic photography: three case studies. J Forensic Sci 46:1438-1441

5. Porter G, Doran G (2000) An anatomical and photographic technique for forensic facial identification. Forensic Sci Int 114:97-105

6. Yoshino M, Matsuda H, Kubota S, Imaizumi K, Miyasaka S (2000) Computer-assisted facial image identification system using a 3-D physiognomic range finder. Forensic Sci Int 109:225-237

7. Lynnerup N, Andersen M, Lauritsen HP (2003) Facial image identification using Photomodeler ${ }^{\mathbb{R}}$. Leg Med 5:156-160

8. Thali MJ, Braun M, Dirnhofer R (2003) Optical 3D surface digitizing in forensic medicine: 3D documentation of skin and bone injuries. Forensic Sci Int 137(2-3):203-208

9. Thali MJ, Braun M, Buck U, Aghayev E, Jackowski C, Vock P, Sonnenschein M, Dirnhofer R (2005) VIRTOPSY-Scientific documentation, reconstruction and animation in forensic: individual and real 3D data based geo-metric approach including optical body/ object surface and radiological CT/MRI scanning. J Forensic Sci 50 (2):428-442

10. Buck U, Naether S, Braun M, Bolliger S, Friederich H, Jackowski C, Aghayev E, Christe A, Vock P, Dirnhofer R, Thali MJ (2007) Application of $3 \mathrm{D}$ documentation and geometric reconstruction methods in traffic accident analysis: with high resolution surface scanning, radiological MSCT/MRI scanning and real data based animation. Forensic Sci Int 170:20-28

11. Thali M, Dirnhofer R, Vock P (2009) The Virtopsy approach. Taylor \& Francis CRC Press, Boca Raton, pp 151-156 